\title{
Sicily and southern Calabria focal mechanism database: a valuable tool for local and regional stress-field determination
}

\author{
Luciano Scarfi, Alfio Messina, Carmelo Cassisi
}

Istituto Nazionale di Geofisica e Vulcanologia, Osservatorio Etneo, Sezione di Catania, Catania, Italy

\author{
Article history \\ Received July 17, 2012; accepted December 12, 2012. \\ Subject classification: \\ Focal mechanisms, Local seismic network, Kinematics, Stress regime, Regional active seismogenic structure.
}

\begin{abstract}
In this work, we present a new catalog of focal mechanisms calculated for earthquakes recorded in Sicily and southern Calabria. It comprises about 300 solutions, for events with magnitudes ranging from 2.7 to 4.8 that occurred from 1999 to 2011. We used P-wave polarities to compute the fault-plane solutions. Two main goals are achieved. For the first, the catalog allows the stress regime and kinematics characterizing the studied area to be depicted at a regional and more local scale. In particular, moving along the tectonic lineament that extends from the Aeolian Islands to the Ionian Sea, there is a change from a regime characterized by sub-horizontal P-axes, ca. NW-SE directed, to an extensive one in the Calabro-Peloritan Arc, where T-axes striking in a NW-SE direction prevail. Our results also show that part of the seismicity is clustered along the main active seismogenic structures, of which the focal mechanisms indicate the kinematics. Finally, in the Etna volcano area, different stress fields act at different depths due to the combination of the regional tectonics, the strong pressurization of the deep magmatic system, and the dynamics of the shallower portion of the volcano. As a second goal, we highlight that the catalog also represents a valuable tool, through the data distribution on the internet, for further studies directed towards improving our understanding of the geodynamic complexity of the region, and for a better characterization of the seismogenic sources.
\end{abstract}

\section{Introduction}

Collision, subduction and active volcanism characterize the lithosphere of southern Italy. Here, geological and geophysical evidence can be interpreted in the framework of a geodynamic model that assumes an approximately N-S convergence between the African and European plates [e.g., D'Agostino and Selvaggi 2004, Serpelloni et al. 2007]. The boundary of these plates runs through Sicily and the Ionian Sea, which gives rise to very complex tectonics, with several lithospheric blocks where all of the structural domains characterizing a collisional belt are exposed. In Sicily, these are represented by the Pelagian-Hyblean foreland, the GelaCatania foredeep, and the Appennine-Maghrebian fold-andthrust chain (Figure 1). A major feature of this region is the active volcanism of two distinct areas: (i) Etna, which is the most active European volcano; and (ii) the Aeolian Islands, which represent the emerged part of a submarine volcanic arc that is located within the Tyrrhenian Sea extensional back arc basin [Malinverno and Ryan 1986]. Other features of the area are the high gradient crustal thinning from the interior of Calabria and Sicily to the Tyrrhenian and Ionian basins [Dèzes and Ziegler 2001], and a lateral change in the geodynamic regime: from continental collision in Sicily, to subduction of the Ionian oceanic lithosphere beneath the Calabrian Arc. This passage corresponds to a transition between the ongoing compressional (western and central Sicily) and extensional (northeastern Sicily and southern Calabria) crustal domains. This last is probably related to the end or the final stage of the Ionian subduction and to the rollback of the slab [Malinverno and Ryan 1986, Faccenna et al. 2001, Neri et al. 2005, Scarfi et al. 2009].

Seismological data are certainly one of the fundamental tools to provide important information for studies concerning the dynamics of an area. In particular, the calculation of the earthquake focal mechanisms is a way to determine the displacement type on seismogenic faults, and to improve our understanding of the stress direction and tectonics of the area. Moreover, source parameters that result from these studies can be used in seismotectonic analyses for the evaluation of seismic hazard.

However, some difficulties are encountered by scientists in collecting these parameters from the literature. Indeed, they are not easily available. Searches must be made through many scientific articles and reports, and often this information is not readily available for analyses using computer codes. For the Mediterranean area, and in particular for the zone considered in this study, Sicily and southern Calabria, the existing catalogs (i.e., the Regional Centroid Moment Tensors of Pondrelli et al. [2006, 2011]; see http:/ / istituto.ingv.it/l-ingv/archivi-e-banche-dati/; and the EMMA database of Vannucci and Gasperini [2003, 2004]) only in- 


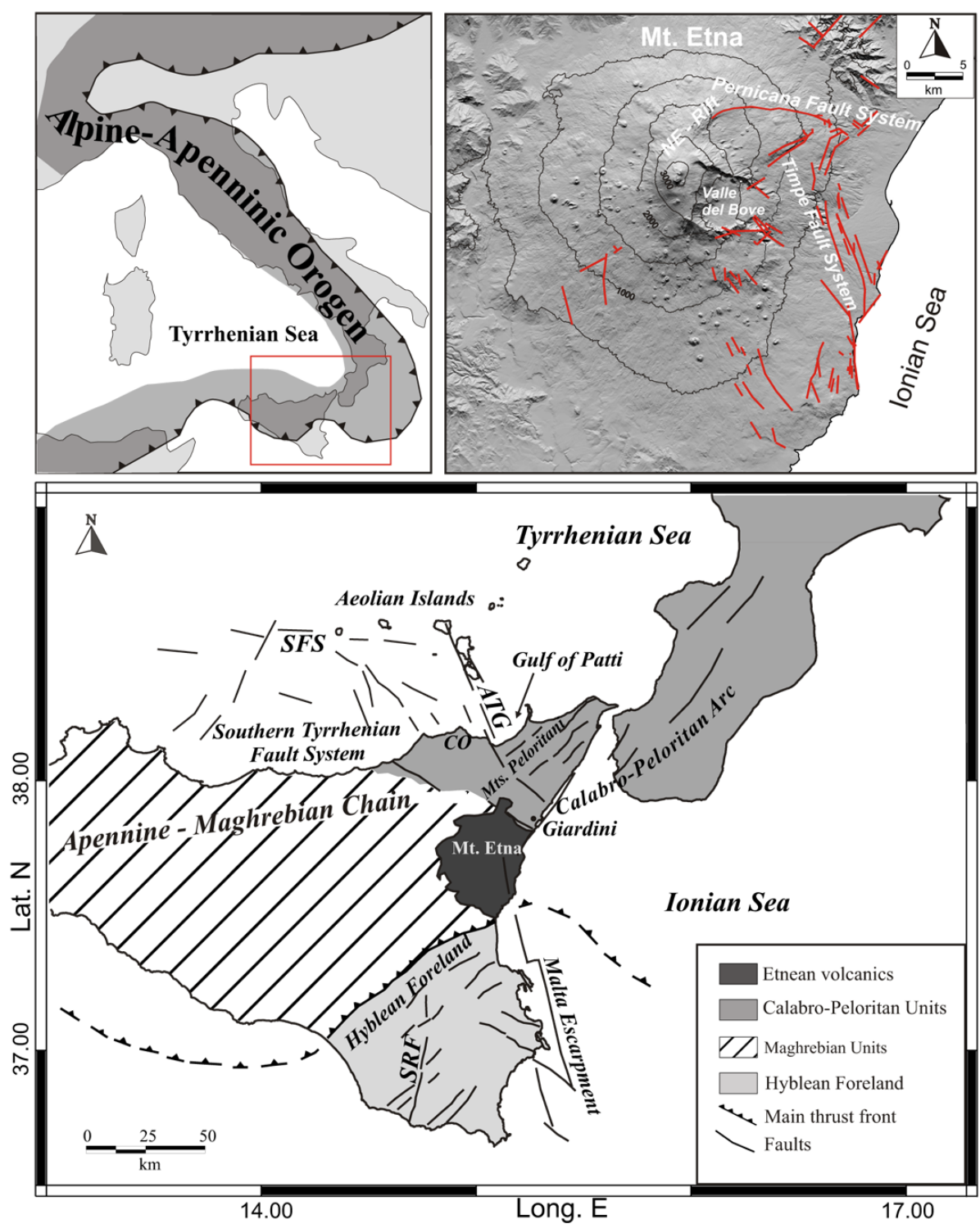

Figure 1. Maps illustrating the main geological and tectonic features of Sicily and southern Calabria. The Etna structural map was modified from Alparone et al. [2011]. SFS, Sisifo Fault System; ATG, Aeolian-Tindari-Giardini Fault System; SRF, Scicli-Ragusa Fault System; CO, Capo d'Orlando.

clude focal solutions for earthquakes with $M \geq 4$. This means that there is an insufficient number of solutions to describe the complicated framework of the seismogenic sources at a local scale. On the other hand, earthquakes of small magnitude provide the much needed information to characterize the tectonic styles of an area well.

Focal mechanism computations are largely performed using the polarities of the P-wave first motion [e.g., Reasenberg and Oppenheimer 1985], which, compared to other methods based on S-waves polarization, $\mathrm{S} / \mathrm{P}$ amplitude ratios, or waveform inversion, has the advantage of making corrections for several factors unnecessary, such as for geometric spreading, attenuation, and site effects. However, the reliability of the solutions obtained (i.e., the ability to constrain the focal planes) depends on the numbers of the available polarities, so that there is good azimuthal coverage around the event source. As the development of modern dense seismic networks over the last decade has made large amounts of data available, it has become possible to compile reliable calculated focal mechanisms for small earthquakes in regional catalogs. Through the use data from a local seismic network managed by the Istituto Nazionale di Geofisica e Vulcanologia (INGV; National Institute for Volcanology and Geophysics), we started a project aimed at creating and maintaining a catalog of fault-plane solutions for events that are located in the area between Sicily and southern Calabria. In this study, we present this new catalog, which can be consulted on the internet. At the same time, we show the seismotectonic patterns that we have inferred from the analysis of our database, both at a regional and a more local scale.

\section{Data and methods}

Since the late 1990's, continuous seismic monitoring activity on Etna, the Aeolian Islands, Hyblean Plateau and the Calabro-Peloritan Arc (CPA) has been performed by seismic stations operating in the framework of the Poseidon Project, which then merged into the INGV in 2001. Between 2003 and 2007, this network was developed and upgraded, and to 


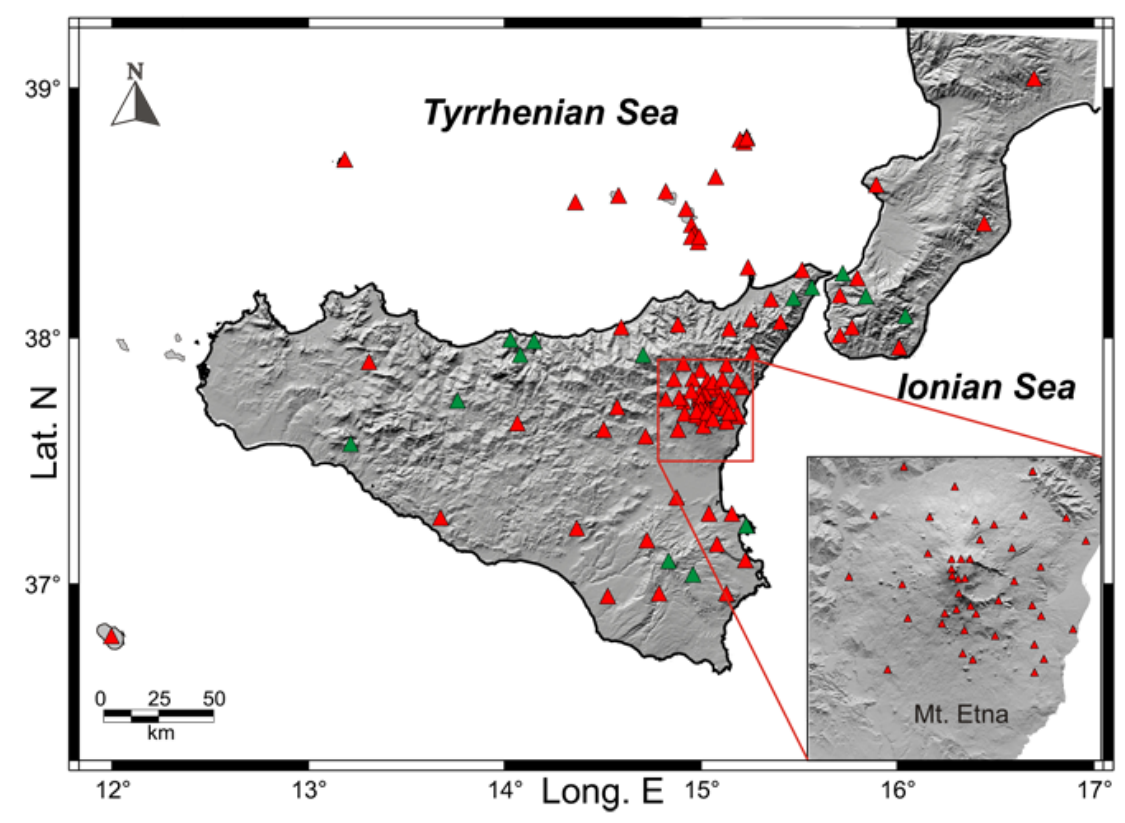

Figure 2. Map of the seismic stations belonging to the local (red) and national (green) networks, as used to compute the focal mechanisms.

date, it consists of about 90 stations, many of which are deployed on Mt. Etna (Figure 2). Almost all are equipped with a broadband (40s) three-component sensor and with a high dynamic digitizer. All of the stations use the same base time, set by GPS time, and the continuously recorded data are transmitted through radio links and V-SAT, to the Acquisition Centre in Catania.

Through this local network, about 10,000 earthquakes were recorded and localized from 1999 to 2011. In Figure 3, we show this seismicity as extracted from the Catalogo dei terremoti della Sicilia Orientale - Calabria Meridionale (1999-2011). INGV, Catania, referred to as the INGV-CT catalog hereinafter (further details about the catalog at: http: / / www.ct. ingv.it/ufs/analisti/catalogolist.php). As well as the earthquakes below the Etna volcano, we note a distribution of events that underlines the most important regional tectonic lineaments: the Southern Tyrrhenian Fault System and the fault belt which runs from the CPA to the Malta Escarpment Fault System (MEFS) in the Ionian Sea, and the faults characterizing the Hyblean Foreland (see Figure 1).

From the INGV-CT catalog, we calculated the focal solutions for the earthquakes shallower than $60 \mathrm{~km}$, using the first-motion P-wave polarities and the well-known FPFIT software [Reasenberg and Oppenheimer 1985]. A magnitude threshold of 2.7 was chosen, considering the values that provided well-constrained focal mechanisms, on the basis of the network configuration and the resulting available polarities. Moreover, we selected the events by taking account of only those with at least 10-15 available polarities, and with sufficient station coverage on the focal sphere (see azimuthal gap and station distribution ratio [STDR] parameters below). To this end, we carefully checked the polarities that might be overlooked by an operator, particularly where the first arrival was emerging, and added others by analyzing the recordings of the National Seismic Network (data source: ISIDe at http:/ / iside.rm.ingv.it).

Figure 4 shows the map and the cross-sections of the earthquakes considered (about 330). Their distribution is relatively well representative of the seismicity of the various areas. The typical seismogenic depth is from very shallow to $10 \mathrm{~km}$ to $15 \mathrm{~km}$ for Etna volcano, and $8 \mathrm{~km}$ to $15 \mathrm{~km}$ for the Aeolian Islands and CPA, while for the other areas it is between $15 \mathrm{~km}$ and $30 \mathrm{~km}$. The hypocentral locations are taken from the INGV-CT catalog, which provides the best possible estimates with the available data and standard location methods (i.e., HYPOELLIPSE; see Lahr [1989]). The associated errors for the selected events are expressed as mean and standard deviation, and are $0.5 \pm 0.4 \mathrm{~km}$ and $0.6 \pm 0.5 \mathrm{~km}$ for the horizontal and vertical coordinates, respectively, and $0.2 \pm 0.1$ $\mathrm{s}$ for the root-mean-square (rms) travel-time residuals. The ray-tracing is calculated using HYPOELLIPSE, with the known velocity structures of the region [see Hirn et al. 1991, Musumeci et al. 2003, Langer et al. 2007, Gambino et al. 2012]. The azimuthal gap is $106^{\circ} \pm 49^{\circ}$, on average.

Starting from the hypocentral parameters and the raytracing, FPFIT finds the double-couple fault-plane solution (source model) by a grid search procedure that best fits a given set of observed first-motion polarities of an earthquake. The software formally estimates the uncertainty in the focal parameters (strike, dip, rake) that result in a misfit score bounding the $90 \%$ confidence interval, and provides other quantities designed to characterize the quality of the final solution (e.g., the numbers of used observations, the STDR). Essentially, we rejected those mechanisms with uncertainties of $>40^{\circ}$ in the focal parameters (the catalog contains very few solutions with variance $>40^{\circ}$ in only one of the fault-plane sets) or with a STDR $<0.4$. The STDR ranges from 0.0 to 1.0 , and it is sensitive to the distribution of the data on the focal 

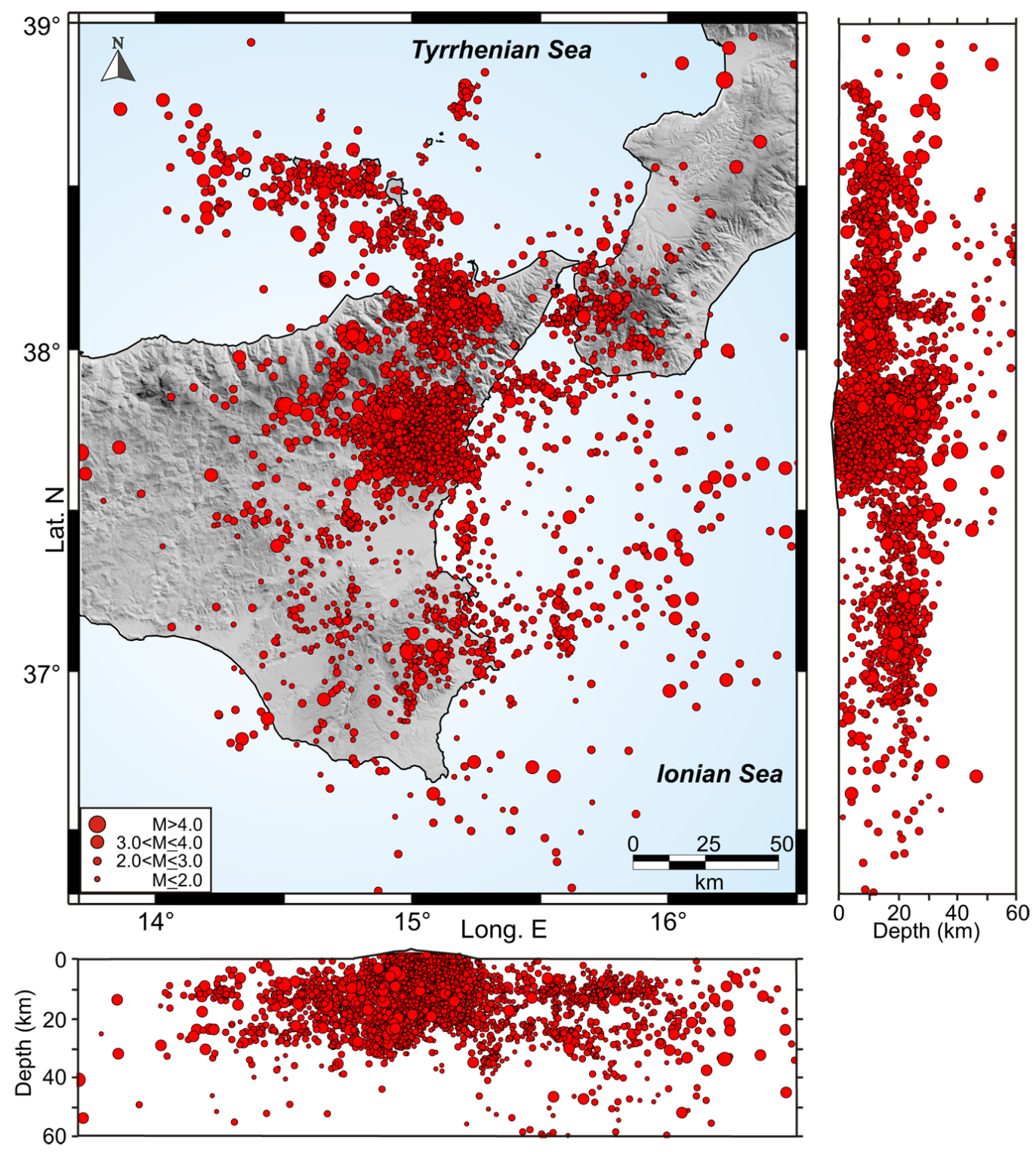

Figure 3. Map view, N-S and W-E cross-sections of the seismicity located by the local network for the period 1999-2011, from the "Catalogo dei terremoti della Sicilia Orientale - Calabria Meridionale (1999-2011). INGV, Catania".

sphere, relative to the radiation pattern; i.e., a solution with a STDR $<0.5$ is less robust than one with a STDR $>0.5$ [see Reasenberg and Oppenheimer 1985, Kilb 2001]. For our solutions STDR is generally higher than 0.6 to 0.7 .

The code adopted in this study also implies (common to most seismological studies) the assumption that the earthquake source can be explained in terms of a shear-fault mechanism known as 'double couple' (DC). However, several studies have shown that an earthquake source can be incompatible with pure shear faulting. Indeed 'non-DC' earthquakes have been observed in many environments, which includes volcanic and geothermal areas in particular, where the non-DC components of their mechanism have been related to fluid dynamics phenomena or source complexity [e.g., Foulger et al. 2004; and references therein]. On Etna, the non-DC source component (20\%-60\%) was determined by analyzing earthquakes that occurred in the period immediately before the 1991-93 and 2001 eruptions [see
Saraò et al. 2001, 2010].

We cannot entirely exclude that some earthquakes might have a source mechanism with a non-DC component, especially among those we analyzed and located on Etna. Further investigations and other methods are needed here. Nevertheless, we can confirm that the distribution of the polarities and the clear presence of S-phases are fully compatible with a DC mechanism, and that, therefore, our solutions can be considered to be at least representative of the shear component of the analyzed seismic events.

Our analysis covers the period from 1999 to 2011, except for Etna volcano, for which the years from 1999 to 2002 will be the objective of a future study, due to the several hundreds of earthquakes stored in the database that were recorded in response to the 2001 and 2002 eruptions.

For further information on the catalog, the quality of the solutions, and how to access the details online, see the Appendix. 


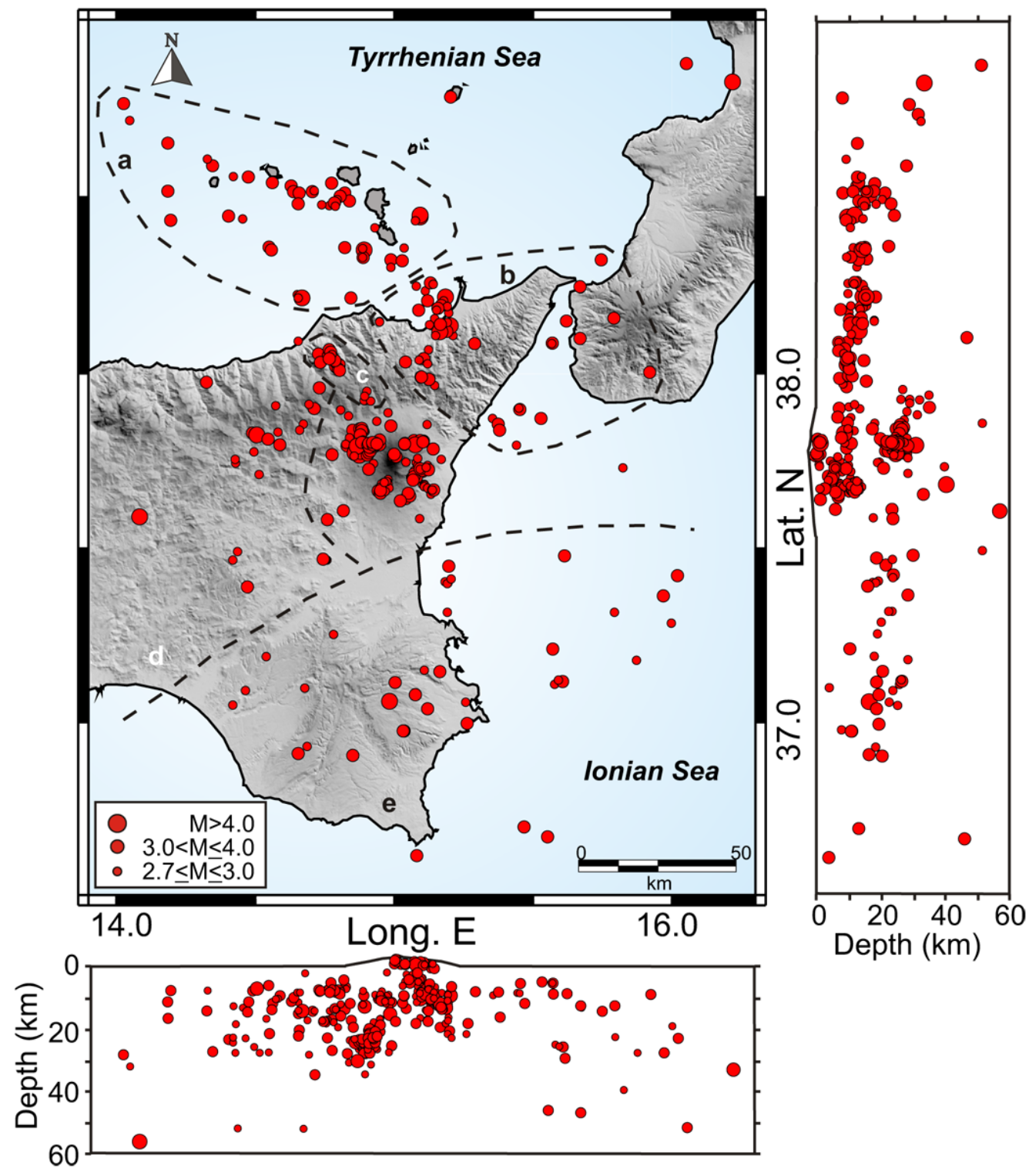

Figure 4. Map view, N-S and W-E cross-sections of the earthquakes selected for the focal mechanism computation. Dotted lines contour sub-areas (indicated by letters) in which the focal mechanisms were divided (see text for details).

\section{Seismotectonic deformation fields}

While individual focal mechanism solutions are not the primary focus of this study, it is worthwhile describing the overall spatial structure of the seismotectonic deformation field, as inferred from the analysis of our catalog. Indeed, we can make the assumption that the earthquake focal mechanisms reflect the state of stress of the studied areas, which implies that at a first approximation, the P-axes and T-axes correspond to the principal stress axes $\sigma 1$ and $\sigma 3$, respectively.

Figures 5 to 9 show the focal mechanisms, their classification according to Zoback [1992], and the orientation of the $\mathrm{P}$-axes and T-axes. Note that we have decided to show and discuss the fault-plane solutions within the Mt. Etna area separately, considering the influence that the magmatic system of the volcano undoubtedly produces on the stress field at various depths. Moreover, the stereonets shown in Figure 6, which represent the direction and plunge of the P-axes and T-axes, are related to the sub-areas traced in Figure 4, which we established by grouping our solutions according to the tectonic zones studied and the similarities of the focal parameters examined.

\subsection{The regional pattern}

From Figures 5 and 6, excluding the CPA, we observe that the Aeolian Islands, eastern Sicily and the Ionian Sea are predominantly characterized by $\mathrm{P}$-axes and T-axes striking in ca. NW-SE and NE-SW directions, respectively. The majority of the events are strike-slip or oblique types (ca. 70\%). Instead, the earthquakes located between the Gulf of Patti and the CPA reveal a clear change in the stress field, as T-axes striking in a NW direction prevail. Moreover, the events here mostly show normal fault mechanisms $(80 \%)$, particularly offshore and onshore of the Gulf of Patti.

As has been highlighted by several geological and geophysical studies, the regional geodynamic processes related to the ca. N-S Africa and Europe convergence are expressed 

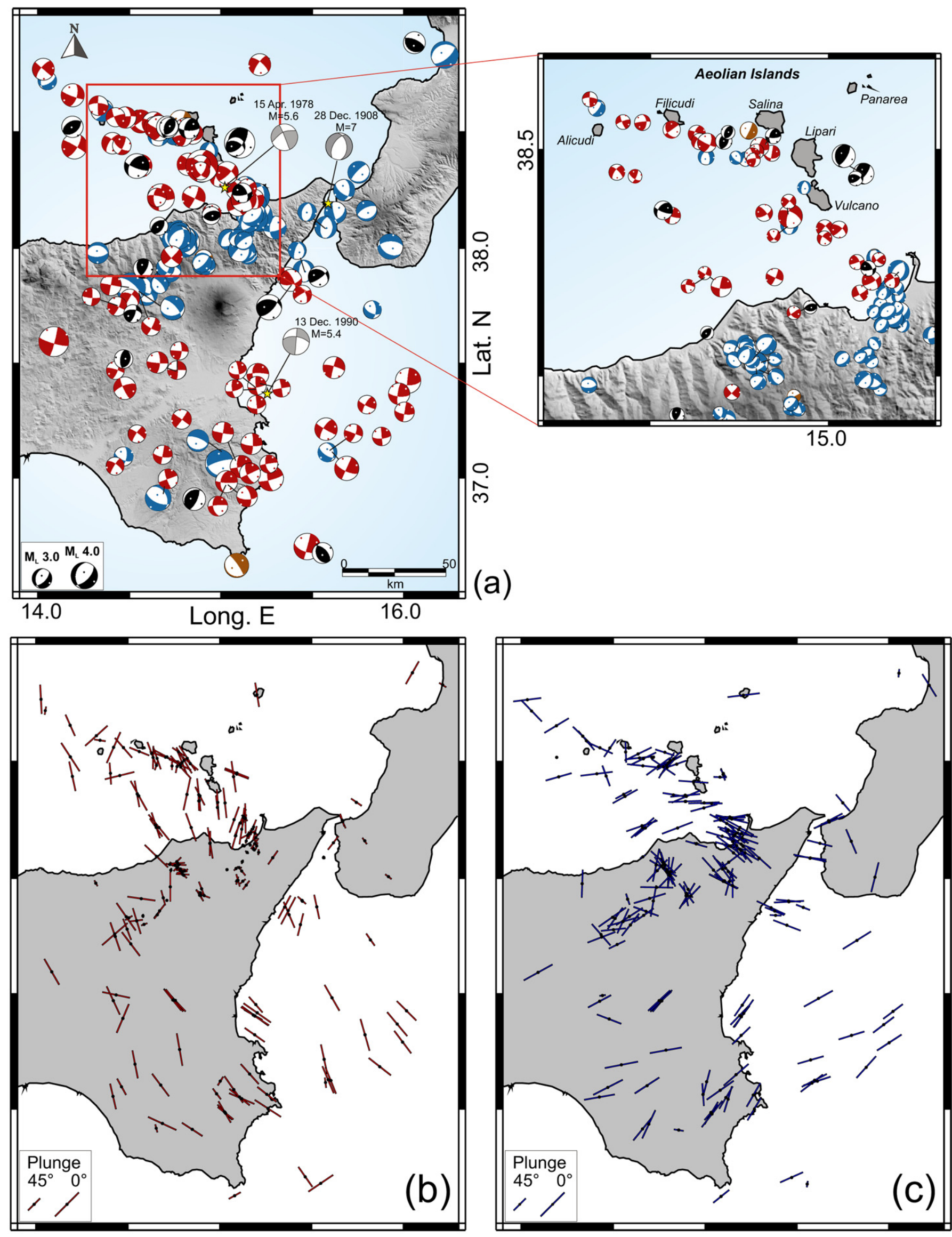

(a)

กิ
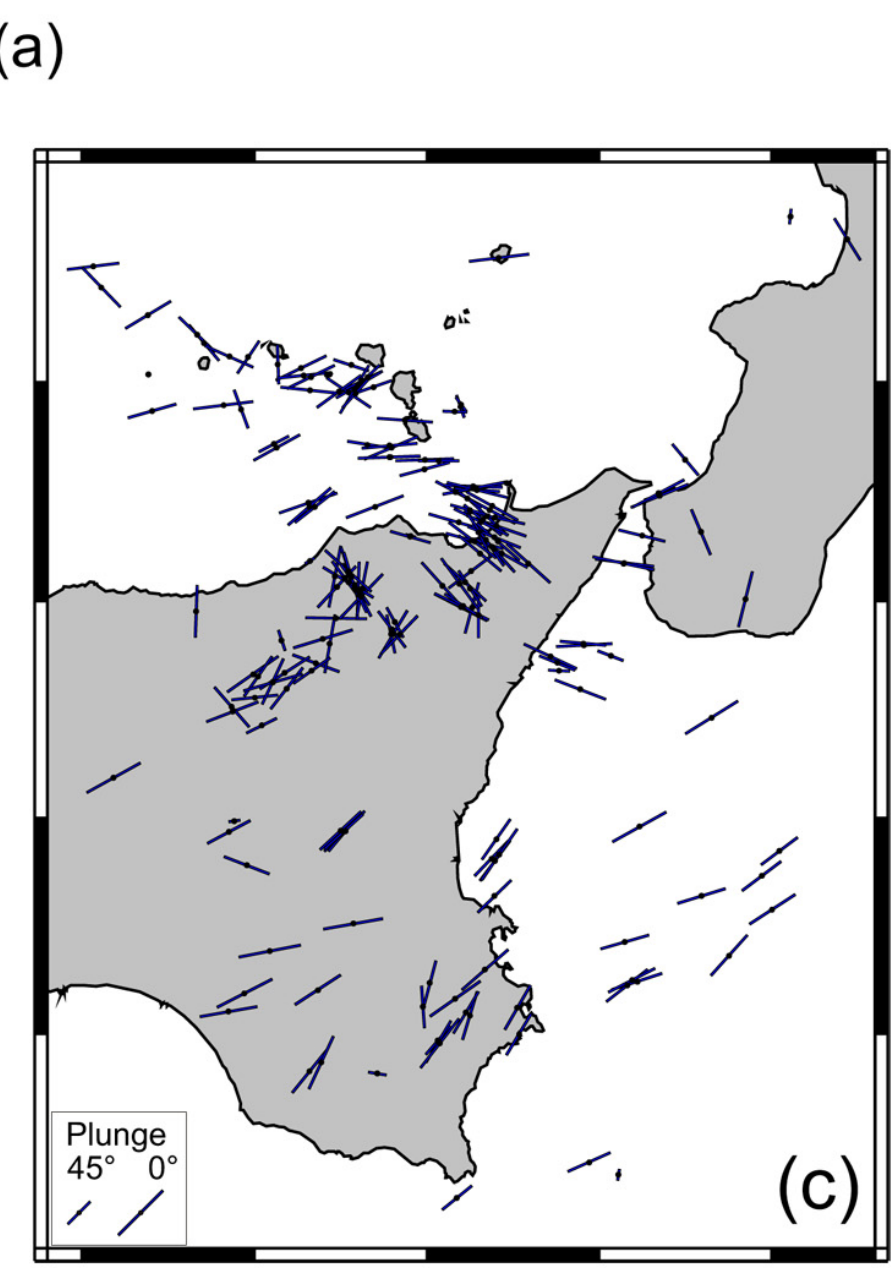

Figure 5. Computed focal mechanisms shown in map (a), with P-axes (b), and T-axes (c). Red, strike-slip fault; blue, normal fault; black. inverse fault; brown, unknown regime, according to the Zoback [1992] classification. The grey fault mechanisms are solutions reported in literature for some of the major earthquakes that occurred in the area [see Gasparini et al. 1982, Amato et al. 1995, Pino et al. 2009]. Note that the solutions for the Etna area are shown in the following figures. 
here by active contraction between the Sicilian-Hyblean and Tyrrhenian blocks, west of the Aeolian Islands-TindariGiardini lineament (ATG; see Figure 1), and by an extension in northeastern Sicily and western Calabria. This latter is oriented about $\mathrm{N} 130^{\circ} \mathrm{E}$, as perpendicular to the $\mathrm{CPA}$ and parallel to the direction of the subduction of the Ionian oceanic crust underneath the CPA [e.g., Ghisetti 1979, Tortorici et al. 1995, Neri et al. 2005, Pepe et al. 2005, Ferranti et al. 2008, Scarfi et al. 2009, Serpelloni et al. 2010, Cuffaro et al. 2011]. The reason for the coexistence of these two deformational domains is far from well understood. The debate on the most appropriate model is still open, and several often contrasting hypotheses have been proposed. These have ranged from rifting to back-arc extension in the Tyrrhenian Sea or regional deep-induced uplift [see e.g., Serpelloni et al. 2010, Palano et al. 2012, for a more detailed discussion and references]. The accommodation between the two domains occurs along the ATG fault, a main regional shear zone that extends from the Ionian Sea, north of Mt. Etna, to the Aeolian Islands [e.g., Neri et al. 2005, Argnani 2009, Billi et al. 2010]. This is considered in some studies to be the northward continuation of the MEFS [Ghisetti 1979, Lanzafame and Bousquet 1997, Govers and Wortel 2005], which is a NNW-SSE-striking Mesozoic lithospheric boundary offshore of southeastern Sicily that is made up of a diffuse transtensional fault system that separates the Ionian oceanic basin from the thick Hyblean continental crust [Westaway 1990, Nicolich et al. 2000].

Apart from the interpretative models, this geodynamic framework outlined here matches relatively well with our observations, which show predominantly normal fault solutions between the Gulf of Patti coastal area, the Messina Strait, and southern Calabria, with NW-SE extensional (T) axes, and westward strike-slip and some thrust faults with NW-SE compressional (P) axes. Moreover, in a narrow band west of the ATG and slightly south of Capo d'Orlando, some earthquake clusters with normal mechanism types and with fault planes striking both in the NE-SW and NW-SE directions appear to indicate the transition between the compressional and extensional domains (Figures 5 and 6c).

In greater detail, several mechanisms illustrate the seismic activity of the main regional tectonic structures. From north to south, in the Aeolian Islands area, dextral strike-slip solutions reveal the kinematics of the Southern Tyrrhenian Fault Systems (Figure 5). In particular, here the geometry traced by the event locations and the orientation of the nodal planes of the fault-plane solutions computed indicate the presence of WNW-ESE and NW-SE oriented structures, which is consistent with the Sisifo and the northern section of the ATG fault systems that characterize the area [see also Gambino et al. 2012]. The occurrence of some earthquakes east of Lipari-Vulcano at about $10 \mathrm{~km}$ in depth with thrust fault mechanisms might be related to a compressive zone that has been generated at the edge between the ca. NW-SE

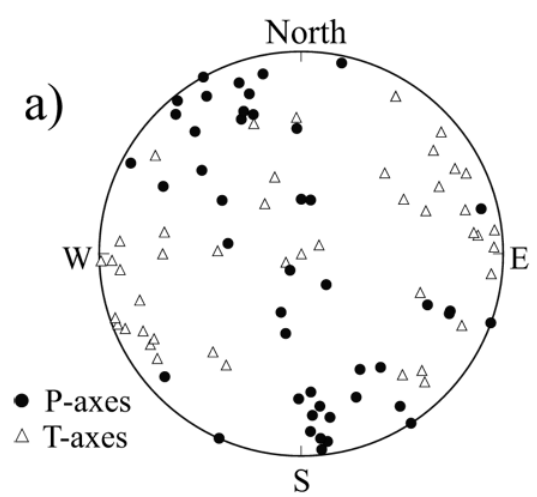

b)

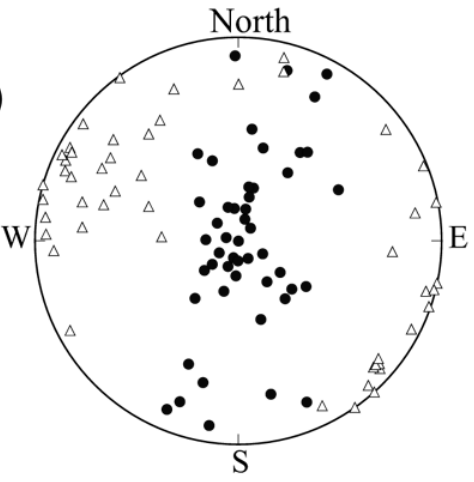

c)
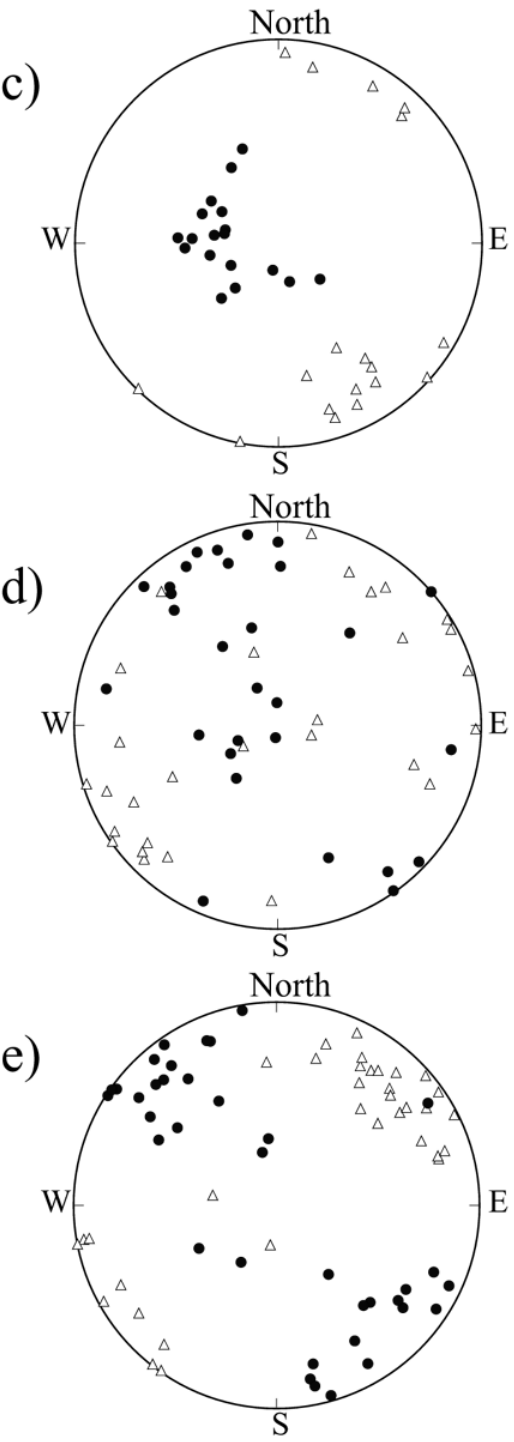

Figure 6. Equal area Schmidt nets of P-axes and T-axes. $a$ to $e$, sub-areas indicated in Figure 4. 
dextral displacement of the ATG and the extension characterizing the southern Tyrrhenian-CPA area.

The extension of the ATG inland is not so seismically obvious, while it has very impressive morphological expression in the Peloritani Mountains, through vertical and rightlateral offset of the Tyrrhenian terraces [Ghisetti 1979]. On the other hand, as mentioned above, an important crustal discontinuity is highlighted by a clear change in the seismic pattern of both sides of the fault lineament. Moreover, the continuation of the ATG to the coast of the Ionian Sea can be recognized through some right-lateral mechanisms of earthquakes located near the town of Giardini, at a depth of about $10 \mathrm{~km}$. Considering also the presence of two inverse solutions, it can be deduced that there is a transpressive zone related to a different deformation pattern that characterizes the MEF and the Ionian Sea area, although we cannot confirm this owing to the small number of events.

Further south, strike-slip movement with one nodal plane striking NNW-SSE to NE-SW is observed in the proximity of the Ionian coast and offshore along the MEFS, with an orientation of the maximum compressive stress axis that is in agreement with the regional compression (Figures 5 and 6e). Westwards, on the Hyblean Plateau, some NNE-SSW left-lateral strike-slip mechanisms can be related to the 'ScicliRagusa' Fault System. These findings match relatively well with other seismological studies [see Musumeci et al. 2005], and also with the GPS measurements, which for southern Sicily show a northwards motion according to a long-term Eurasia-Nubia convergence, and a small but detectable extension orthogonal to the Sicily Channel [e.g., Mattia et al. 2012, Palano et al. 2012].

Recent studies have also indicated a NW-SE contraction between the frontal thrust belt of the ApennineMaghrebian Chain and the Hyblean Plateau [Ferranti et al. 2008, Devoti et al. 2011], and that E-W striking normal faults and NNE-SSW-striking right-lateral faults that cut the northern rim of the plateau have been reactivated in reverse motion over the last $0.85 \mathrm{Myr}$ [Catalano et al. 2008]. Unfortunately, the limited focal mechanisms available on the frontal belt of southern Sicily preclude any confirmation of these processes in this sector.

Finally, Figure 5 shows focal mechanism solutions that are reported in literature for some major earthquakes that occurred in the area [see Gasparini et al. 1982, Amato et al. 1995, Pino et al. 2009]; comparisons with our calculated mechanisms indicate similarities in the displacement type.

\subsection{The Mt. Etna pattern}

On Mt. Etna, different stress fields can act at different depths due to the combination of the regional tectonics, the strong pressurization of the magmatic system [Cocina et al. 1998, Patanè and Privitera 2001, Barberi et al. 2004, Patanè et al. 2004], the dynamics of the shallower portion of the vol- cano, and in particular, the marked displacement of its eastern flank [e.g. Puglisi and Bonforte 2004, Rust et al. 2005, Solaro et al. 2010, Bonforte et al. 2011]. To better investigate this issue, we analyzed the focal mechanisms by separating them into three different depth levels: down to $3 \mathrm{~km}$ and $10 \mathrm{~km}$, and below $10 \mathrm{~km}$. This was based on the consideration that other studies have assumed a possible pressurization source at $3 \mathrm{~km}$ to $5 \mathrm{~km}$ in depth [Bonaccorso et al. 2005, Bonaccorso et al. 2006, Bonforte et al. 2008, Bruno et al. 2012], and a transition between regional and local stress fields at $10 \mathrm{~km}$ to $15 \mathrm{~km}$ in depth, beneath the volcano [Cocina et al. 1998, Patanè and Privitera 2001].

At the shallower level (Figure 7) northwards, a group of focal mechanisms can be distinguished that are mostly strikeslip, and are related to events no deeper than $1 \mathrm{~km}$ b.s.l., which depict well the kinematics of the 'NE Rift' and the 'Pernicana Fault' System (see Figure 1). Characterized by left-lateral, oblique-slip movements, this dissects the entire northeastern flank of Mt. Etna and it is widely recognized as a structural limit between a severely unstable sector to the south and a stable area to the north, thus controlling the seawards movement of the eastern flank of the volcano [e.g., Acocella and Neri 2005, Solaro et al. 2010, Azzaro et al. 2012]. The system is seismically very active, and it is also characterized by frequent shallow seismicity [Alparone et al. 2013]. Most of the other focal solutions at this depth range can be related to these kinds of dynamics too, which act through the fault belt of mainly extensional structures that characterize the eastern flank of the volcano [see Azzaro et al. 2012].

At the intermediate depth $(3-10 \mathrm{~km})$, the earthquakes analyzed are again mainly located in the eastern flank (Figure 8) at a depth of $4 \mathrm{~km}$ to $7 \mathrm{~km}$. The focal mechanisms are mostly strike-slip and oblique-slip (70\%), and they show a slightly radial distribution of the P-axes, with respect to the craters. Similar results were reported by Alparone et al. [2011], who analyzed the seismic patterns before the onset of the 2004-2005 eruption, and explained this trend as due to the effects of a pressurizing source (the feeding system of the volcano) that is located at a depth of between $3 \mathrm{~km}$ and $5 \mathrm{~km}$. Several other studies have used GPS measurements to model a spreading source beneath the upper southeastern flank of the volcano at a depth of $4 \mathrm{~km}$ to $5 \mathrm{~km}$ that can be induced by the pressurizing of the plumbing system. This would cause an areal dilatation during inflation periods, and it would act chiefly on the instability of the eastern flank of Etna, favoring its continuing eastwards sliding [e.g., Bonaccorso et al. 2005, Bonaccorso et al. 2006, Bonforte et al. 2008, Bruno et al. 2012]. Our findings might support such a model.

Finally, in the deeper portion of the crust, the calculated focal solutions are for events located in two small areas; i.e., in the northeastern and central-southern sectors of the volcano (Figure 9). Most of the earthquakes have occurred as 

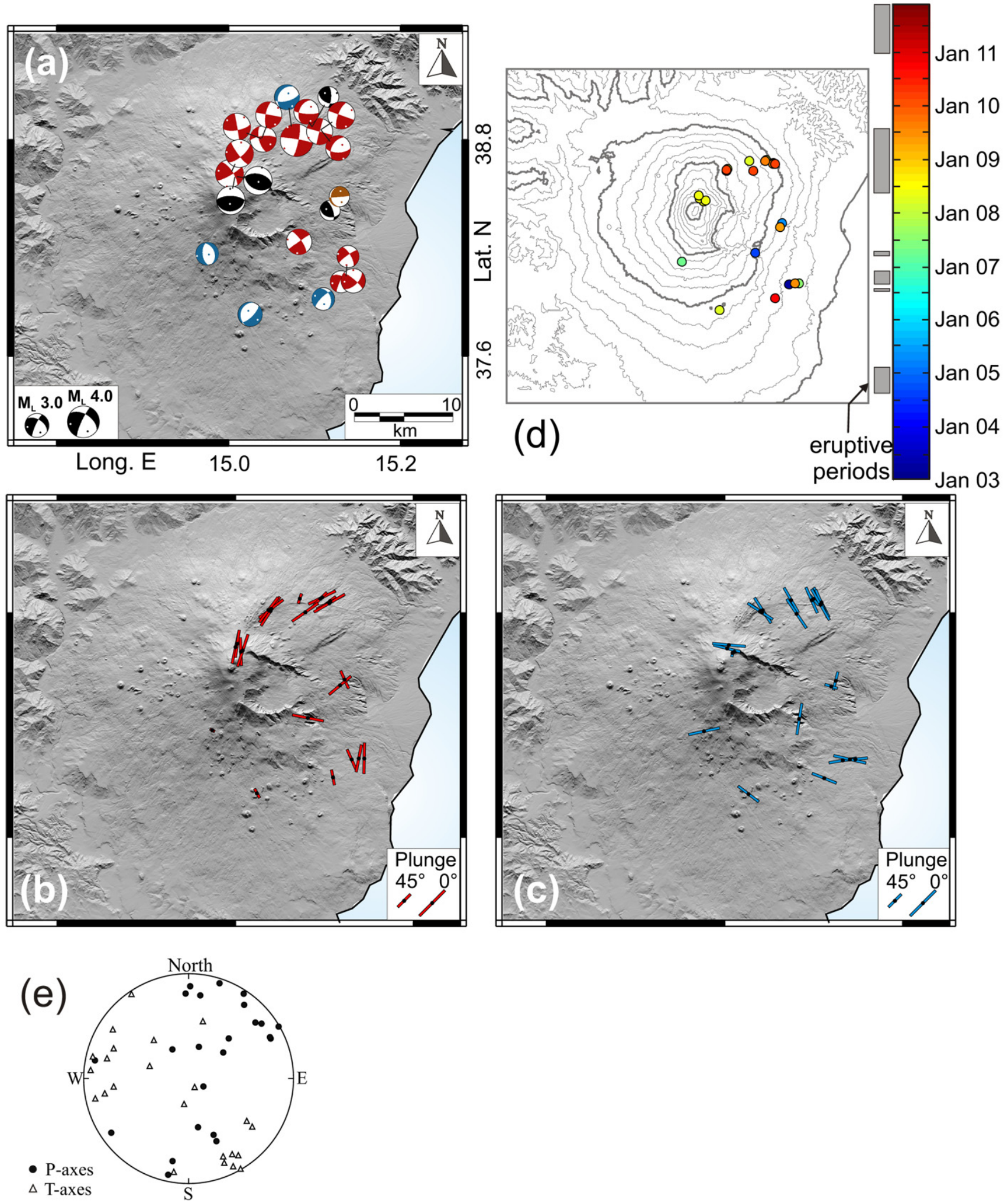

Figure 7. (a) Focal solutions for the shallower earthquakes (-1.0 to $3.0 \mathrm{~km}$ b.s.1.) in the Etna area. (b) P-axes. (c) T-axes. (d) Map and time occurrences of the related events. (e) Stereonet of the P-axes and T-axes.

swarms. The events of the northeastern cluster are $20 \mathrm{~km}$ to $30 \mathrm{~km}$ deep and they mainly show oblique or strike-slip fault mechanisms with P-axes striking NW-SE. Given their depth and the orientation of the compression axes $(\mathrm{P})$, they are probably related to regional tectonic structures. The other cluster is $10 \mathrm{~km}$ to $13 \mathrm{~km}$ deep, with P-axes uniformly directed NE-SW of a strike-slip fault type. The occurrence of deep seismicity in this sector of the volcano was related to shear failure of seismogenic structures as the response to a continuous injection of magma from depth into the shallow reservoir (3-5 km in depth) [see Patanè et al. 2003]. Since several events of this cluster were recorded in January and May in 2006, before the July eruption, it is likely that our analyzed seismicity refers to the same dynamics. 

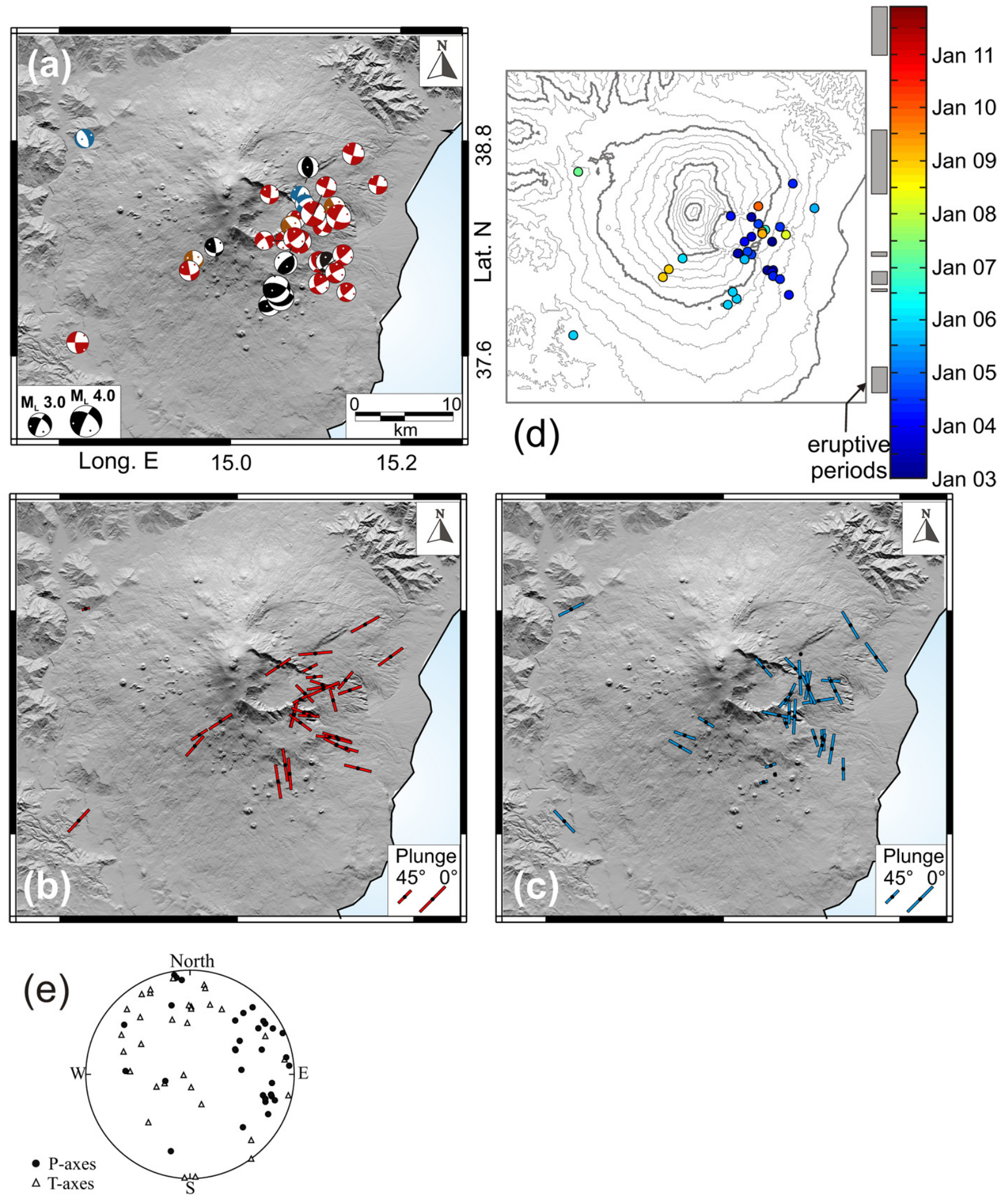

Figure 8. As for Figure 7, for the earthquakes of $3.0 \mathrm{~km}$ to $10 \mathrm{~km}$ in depth.

\section{Conclusions}

In this study, we present a new catalog of focal mechanisms that has been calculated for earthquakes with magnitude from 2.7 that were recorded by the local seismic network in Sicily and southern Calabria. To date, the cata$\log$ comprises ca. 300 solutions for events $\left(2.7<\mathrm{M}_{\mathrm{L}}<4.8\right)$ that occurred between 1999 and 2011. This analyzing of our data provides an overview of the stress regime and kine-

matics that characterize the studied area, at a regional and more local scale. In particular, we can clearly see the compressive regime that is NW-SE directed and that characterizes Sicily westward of the 'Aeolian-Tindari-Giardini' lineament, which changes to an extensive regime that is NW-SE directed in the CPA. Several normal faults detected between Capo d'Orlando and Etna that strike in both the NE-SW and NW-SE directions appear to reveal the transi- 

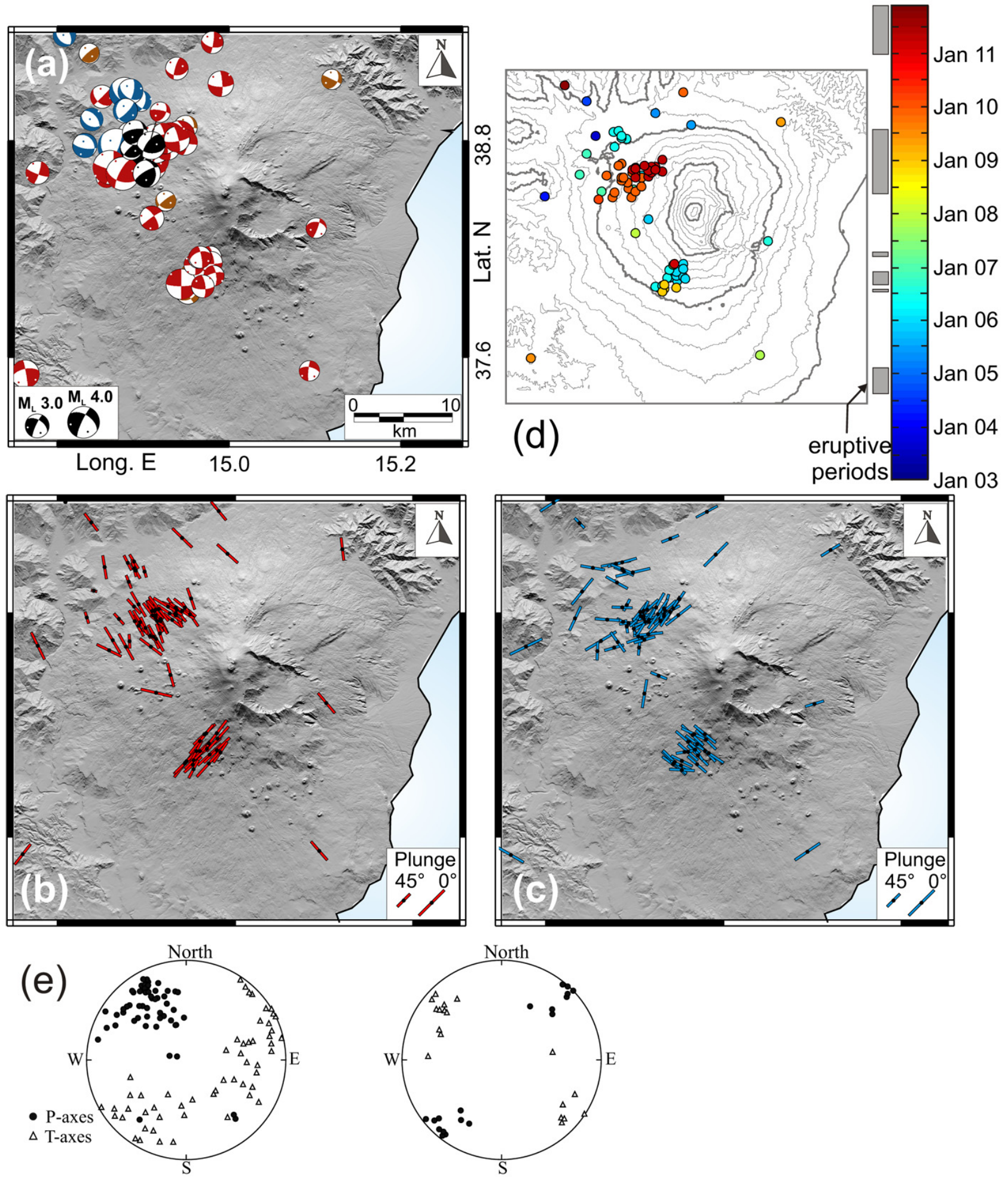

Figure 9. A for Figure 7, for the earthquakes with depth $>10 \mathrm{~km}$. (e) Stereonets refer to the northern (left) and southern (right) clusters.

tion zone between compressional and extensional domains.

Our data also show that part of the seismicity is clustered along active seismogenic structures, hence underlining their important role in the regional dynamics. In the Aeolian Island zone, dextral strike-slip faults are evidence of the ATG, the continuation of which is probably marked by the occurrence of some earthquakes with a similar mechanism in the Ionian Sea, near the town of Giardini. Strike-slip faulting is observed in the proximity of the Ionian coast and offshore along the MEFS. Westwards, in the Hyblean Foreland, some NNE-SSW left-lateral strike-slip mechanisms can be related to the 'Scicli-Ragusa' Fault System.

In Etna volcano, there are different stress fields acting at different depths. In particular, at the shallower and intermediate levels (down to $3 \mathrm{~km}$ and $10 \mathrm{~km}$ ), the stress field is governed by the combination of the strong pressurization of the 
magmatic system and the dynamics of the shallower structures of the volcano, whereas at greater depths, the regional dynamics are again the main driving force.

In addition to these findings, we can also emphasize that our database can be considered a valuable and essential tool for all advanced studies that are aimed at improving the knowledge of the geodynamics of the region. Indeed, the data are freely available (see the Appendix) and can be represented as they are or reprocessed by different techniques.

In future studies, we plan to maintain and expand this catalog to provide a comprehensive record of the source parameters for the region. Moreover, calculation of the focal mechanisms in the Etna volcano from 1999 to 2002 will also be pursued, to complete the database.

Acknowledgements. We are grateful to the colleagues of the Gruppo di analisi sismica of INGV Catania, and to R. Distefano for providing data to this project. We wish to thank R. Azzaro for his suggestions and for having supported this work, and likewise M. Aliotta, B. Behncke, S. Mangiagli, P. Montalto and M. Palano for providing some resources. A. Saraò and an anonymous reviewer are kindly acknowledged for their stimulating comments and suggestions. We also thank S. Conway for correcting and improving the English language of this article. Some maps and the focal mechanisms have been plotted with GMT [Wessel and Smith 1998].

\section{References}

Acocella, V., and M. Neri (2005). Structural features of an active strike-slip fault on the sliding flank of Mt. Etna (Italy), J. Struct. Geol., 27, 343-355.

Alparone, S., G. Barberi, A. Bonforte, V. Maiolino and A. Ursino (2011). Evidence of multiple strain fields beneath the eastern flank of Mt. Etna volcano (Sicily, Italy) deduced from seismic and geodetic data during 2003-2004, B. Volcanol., 73 (7), 869-885; doi:10.1007/ s00445-011-0456-1.

Alparone, S., O. Cocina, S. Gambino, A. Mostaccio, S. Spampinato, T. Tuvè and A. Ursino (2013). Seismological features of the Pernicana-Provenzana Fault System (Mt. Etna, Italy) and implications for the dynamics of northeastern flank of the volcano, J. Volcanol. Geotherm. Res., 251, 16-26; doi:10.1016/j.jvolgeores.2012.03.010.

Amato, A., R. Azzara, A. Basili, C. Chiarabba, M. Cocco, M. Di Bona and G. Selvaggi (1995). Main shock and aftershocks of the December 13, 1990, eastern Sicily earthquake, Annali di Geofisica, 38 (2), 255-266.

Argnani, A. (2009). Evolution of the southern Tyrrhenian slab tear and active tectonics along the western edge of the Tyrrhenian subducted slab, Geol. Soc., London, Spec. Publ., 311, 193-212.

Azzaro, R., S. Branca, K. Gwinner and M. Coltelli (2012). The volcano-tectonic map of Etna volcano, 1:100.000 scale: an integrated approach based on a morphotectonic analysis from high-resolution DEM constrained by geologic, active faulting and seismotectonic data, Ital. J. Geosci., 131; doi:10.3301/IJG.2011.29.

Barberi, G., O. Cocina, V. Maiolino, C. Musumeci and E.
Privitera (2004). Insight into Mt. Etna (Italy) kinematics during the 2002-2003 eruption as inferred from seismic stress and strain tensors, Geophys. Res. Lett., 31, L21614; doi:10.1029/2004GL020918.

Billi, A., D. Presti, B. Orecchio, C. Faccenna and G. Neri (2010). Incipient extension along the active convergent margin of Nubia in Sicily, Italy: Cefalù-Etna seismic zone, Tectonics, 29, TC4026; doi:10.1029/2009TC002559.

Bonaccorso, A., S. Cianetti, C. Giunchi, E. Trasatti, M. Bonafede and E. Boschi (2005). Analytical and 3-D numerical modelling of Mt. Etna (Italy) volcano inflation, Geophys. J. Int., 163, 852-862; doi:10.1111/j.1365-246X.2005.02777.x.

Bonaccorso, A., A. Bonforte, F. Guglielmino, M. Palano and G. Puglisi (2006). Composite ground deformation pattern forerunning the 2004-2005 Mount Etna eruption, J. Geophys. Res., 111, B12207; doi:10.1029/2005JB004206.

Bonforte, A., A. Bonaccorso, F. Guglielmino, M. Palano and G. Puglisi (2008). Feeding system and magma storage beneath Mt. Etna as revealed by recent inflation/ deflation cycles, J. Geophys. Res., 113, B05406; doi:10.1029/2007JB 005334.

Bonforte, A., F. Guglielmino, M. Coltelli, A. Ferretti and G. Puglisi (2011). Structural assessment of Mount Etna volcano from permanent scatterers analysis, Geochem. Geophys. Geosyst., 12; doi:10.1029/2010GC003213.

Bruno, V., M. Mattia, M. Aloisi, M. Palano, F. Cannavò and W.E. Holt (2012). Ground deformations and volcanic processes as imaged by CGPS data at Mt. Etna (Italy) between 2003 and 2008, J. Geophys. Res., 117, B07208; doi:10.1029/2011JB009114.

Catalano, S., G. De Guidi, G. Romagnoli, S. Torrisi, G. Tortorici and L. Tortorici (2008). The migration of plate boundaries in SE Sicily: influence on the large-scale kinematic model of the African promontory in southern Italy, Tectonophysics, 449, 41-62; doi:10.1016/j.tecto.2007.12. 003.

Cocina, O., G. Neri, E. Privitera and S. Spampinato (1998). Seismogenic stress field beneath Mt. Etna (south Italy) and possible relationships with volcano-tectonic features, J. Volcanol. Geotherm. Res., 83, 335-348.

Cuffaro, M., F. Riguzzi, D. Scrocca and C. Doglioni (2011). Coexisting tectonic settings: The example of the southern Tyrrhenian Sea, Int. J. Earth Sci., 100, 1915-1924; doi:10.1007/s00531-010-0625-z.

D'Agostino, N., and G. Selvaggi (2004). Crustal motion along the Eurasia-Nubia plate-boundary in the Calabrian Arc and Sicily and active extension in the Messina Straits from GPS measurements, J. Geophys. Res., 109, B11402; doi:10.1029/2004 JB002998.

D'Amico, S., B. Orecchio, D. Presti, L. Zhu, R.B. Herrmann and G. Neri (2010). Broadband waveform inversion of moderate earthquakes in the Messina Straits, southern Italy, Phys. Earth Planet. Int., 179, 97-106; doi:10.1016/j. 
pepi.2010.01.012

Devoti, R., A. Esposito, G. Pietrantonio, A.R. Pisani and F. Riguzzi (2011). Evidence of large-scale deformation patterns from GPS data in the Italian subduction boundary, Earth Planet. Sci. Lett., 311, 230-241; doi:10.1016/j.epsl. 2011.09.034.

Dèzes, P., and P.A. Ziegler (2001). European Map of the Mohorovicic discontinuity, in: 2nd EUCOR-URGENT Workshop (Upper Rhine Graben Evolution and Neotectonics), Mt. St. Odile, France.

Faccenna, C., T.W. Becker, F.P. Lucente, L. Jolivet and F. Rossetti (2001). History of subduction and back-arc extension in the central Mediterranean, Geophys. J. Int., 145, 809-820.

Ferranti, L., J.S. Oldow, B. D'Argenio, R. Catalano, D. Lewis, E. Marsella, G. Avellone, L. Maschio, G. Pappone, F. Pepe and A. Sulli (2008). Active deformation in southern Italy, Sicily and southern Sardinia from GPS velocities of the Peri-Tyrrhenian Geodetic Array (PTGA), Boll. Soc. Geol. Ital., 127, 299-316.

Foulger, G.R., B.R. Julian, D.P. Hill, A.M. Pitt, P.E. Malin and E. Shalev (2004). Non-double-couple microearthquakes at Long Valley caldera, California, provide evidence for hydraulic fracturing, J. Volcanol. Geotherm. Res., 132, 45-71.

Gambino, S., V. Milluzzo, A. Scaltrito and L. Scarfi (2012). Relocation and focal mechanisms of earthquakes in the south-central sector of the Aeolian Archipelago: new structural and volcanological insights, Tectonophysics, 524-525, 108-115; doi:10.1016/j.tecto.2011.12.024.

Gasparini, C., G. Iannacone, P. Scandone and R. Scarpa (1982). Seismotectonics of the Calabrian Arc, Tectonophysics, 82, 267-286.

Ghisetti, F. (1979). Relazione tra strutture e fasi trascorrenti e distensive lungo i sistemi Messina-Fiumefreddo, Tindari-Letojanni e Alia-Malvagna (Sicilia nord-orientale): uno studio microtettonico, Geol. Romana, 18, 23-58.

Govers, R., and M.J.R. Wortel (2005). Lithosphere tearing at STEP faults: response to edges of subduction zones, Earth Planet. Sci. Lett., 236, 505-523; doi: 10.1016/j.epsl. 2005.03.022.

Hirn A., A. Nercessian, M. Sapin, F. Ferrucci and G. Wittlinger (1991). Seismic heterogeneity of Mt. Etna: structure and activity, Gephys J. Int., 105, 139-153.

Kilb, D. (2001). Fault parameter constraints using relocated earthquakes: implications for stress change calculations, EOS 82, F811.

Lahr, J.C. (1989). HYPOELLIPSE/VERSION 2.0: A computer program for determining local earthquake hypocentral parameters, magnitude, and first motion pattern, U.S. Geol. Survey, Open-File Report 89/116, 81 pp.

Langer, H., R. Raffaele, A. Scaltrito and L. Scarfi (2007). Estimation of an optimum velocity model in the Peloritani Mountains - assessment of the variance of model parameters and variability of earthquake locations, Geo- phys. J. Int. 170, 1151-1164; doi:10.1111/j.1365-246X.2007. 03459.x.

Lanzafame, G., and J.C. Bousquet (1997). The Maltese escarpment and its extension from Mt. Etna to the Aeolian Islands (Sicily): Importance and evolution of a lithosphere discontinuity, Acta Vulcanol., 9, 113-120.

Malinverno, A., and W.B.F. Ryan (1986). Extension in the Tyrrhenian Sea and shortening in the Apennines as result of arc migration driven by sinking of the lithosphere, Tectonics, 5, 227-245.

Mattia, M., V. Bruno, F. Cannavò and M. Palano (2012). Evidence of a contractional pattern along the northern rim of the Hyblean Plateau (Sicily, Italy) from GPS data, Geologica Acta, 10, 63-70; doi: 10.1344/105.000001705

Musumeci, C., G. Di Grazia and S. Gresta (2003). Minimum 1 -D velocity model in southeastern Sicily (Italy) from local earthquake data, J. Seismol. 7, 469-478.

Musumeci, C., D. Patanè, L. Scarfi and S. Gresta (2005). Stress directions and shear-wave anisotropy: observations from local earthquakes in southeastern Sicily, Italy, B. Seismol. Soc. Am., 95, 1359-1374; doi:10.1785/0120040108.

Neri, G., G. Barberi, G. Oliva and B. Orecchio (2005). Spatial variations of seismogenic stress orientations in Sicily, south Italy, Phys. Earth Planet. Int., 148, 175-191.

Nicolich, R., M. Laigle, A. Hirn, L. Cernobor and J. Gallard (2000). Crustal structure of the Ionian margin of Sicily: Etna volcano in the frame of regional evolution, Tectonophysics, 329, 121-139; doi:10.1016/S0040-1951(00)00192-X.

Palano, M., L. Ferranti, C. Monaco, M. Mattia, M. Aloisi, V. Bruno, F. Cannavò and G. Siligato (2012). GPS velocity and strain fields in Sicily and southern Calabria, Italy: updated geodetic constraints on tectonic block interaction in the central Mediterranean, J. Geophys. Res., 117, B07401; doi:10.1029/2012JB009254.

Patanè, D., and E. Privitera (2001). Seismicity related to 1989 and 1991-93 Mt. Etna (Italy) eruptions: kinematic constraints by fault solution analysis, J. Volcanol. Geotherm. Res., 109, 77-98.

Patanè, D., C. Chiarabba, P. De Gori and A. Bonaccorso (2003). Magma ascent and the pressurization of Mt Etna's volcanic system, Science, 299, 2061-2063.

Patanè, D., O. Cocina, S. Falsaperla, E. Privitera and S. Spampinato (2004). Mt Etna volcano: a seismological framework, In: A. Bonaccorso, S. Calvari, M. Coltelli, C. Del Negro and S. Falsaperla (eds.), Mt. Etna: Volcano Laboratory, AGU Monograph, 148, 147-165.

Pepe, F., A. Sulli, G. Bertotti and R. Catalano (2005). Structural highs formation and their relationship to sedimentary basins in the north Sicily continental margin (southern Tyrrhenian Sea): implication for the Drepano Thrust Front, Tectonophysics, 409, 1-18.

Pino, N.A., A. Piatanesi, G. Valensise and E. Boschi (2009). The 28 December 1908 Messina Straits earthquake (Mw 
7.1): A great earthquake throughout a century of seismology, Seismol. Res. Lett., 80, 243-259; doi:10.1785/gssrl. 80.2.243.

Pondrelli, S., S. Salimbeni, G. Ekström, A. Morelli, P. Gasperini and G. Vannucci (2006). The Italian CMT dataset from 1977 to the present, Phys. Earth Planet. Int., 159, 286-303; doi:10.1016/j.pepi.2006.07.008.

Pondrelli, S., S. Salimbeni, A. Morelli, G. Ekström, L. Postpischl, G. Vannucci and E. Boschi (2011). EuropeanMediterranean Regional Centroid Moment Tensor Catalog: solutions for 2005-2008, Phys. Earth Planet. Int., 185, 74-81; doi:10.1016/j.pepi.2011.01.007.

Puglisi, G., and A. Bonforte (2004). Dynamics of Mount Etna Volcano inferred from static and kinematic GPS measurements, J. Geophys. Res., 109, B11404; doi:10.1029/2003 JB002878.

Reasenberg, P., and D. Oppenheimer (1985). FPFIT, FPPLOT, and FPPAGE: FORTRAN computer programs for calculating and displaying fault plane solutions, U.S. Geol. Surv. Open File Rep, 85/739, 109 pp.

Rust, D., B. Behncke, M. Neri and A. Ciocanel (2005). Nested zones of instability in the Mount Etna volcanic edifice, Sicily, J. Volcanol. Geotherm. Res., 144, 137-153; doi:10. 1016/j.jvolgeores.2004.11.021.

Saraò, A., G.F. Panza, E. Privitera and O. Cocina (2001). Nondouble-couple mechanisms in the seismicity preceding 1991-1993 Etna volcano eruption, Geophys. J. Int., 145, 319-335.

Saraò, A., O. Cocina, E. Privitera and G.F. Panza (2010). The dynamics of the 2001 Etna eruption as seen by full moment tensor analysis, Geophys. J. Int., 181, 951-965; doi: 10.1111/j.1365-246X.2010.04547.x.

Scarfi, L., H. Langer and A. Scaltrito (2009). Seismicity, seismotectonics and crustal velocity structure of the Messina Strait (Italy), Phys. Earth Planet. Int., 177, 65-78; doi:10.1016/j.pepi.2009.07.010.

Serpelloni, E., G. Vannucci, S. Pondrelli, A. Argnani, G. Casula, M. Anzidei, P. Baldi and P. Gasperini (2007). Kinematics of the western Africa-Eurasia plate boundary from focal mechanisms and GPS data, Geophys. J. Int., 169, 1180-1200; doi:10.1111/j.1365-246X.2007.03367.x.

Serpelloni, E., R. Bürgmann, M. Anzidei, P. Baldi, B. Mastrolembo Ventura and E. Boschi (2010). Strain accumulation across the Messina Straits and kinematics of Sicily and Calabria from GPS data and dislocation modelling, Earth Planet. Sci. Lett., 298, 347-360; doi:10.1016/j.epsl. 2010.08.005.

Solaro, G., V. Acocella, S. Pepe, J. Ruch, M Neri and E. Sansosti (2010). Anatomy of an unstable volcano through InSAR data: multiple processes affecting flank instability at Mt. Etna in 1994-2008, J. Geophys. Res., 115, B10405; doi: $10.1029 / 2009$ JB000820.

Tortorici, L., O. Cocina, C. Monaco and C. Tansi (1995). Re- cent and active tectonics of the Calabrian Arc (southern Italy), Tectonophysics, 243, 37-55; doi: 10.1016/00401951(94)00190-K.

Vannucci, G., and G. Gasperini (2003). A database of revised fault plane solutions for Italy and surrounding regions, Comput. Geosci., 29, 903-909; doi:10.1016/S0098-3004(03) 00094-3.

Vannucci, G., and G. Gasperini (2004). The database of Earthquake Mechanisms of the Mediterranean Area (EMMA): a call for contributions, CSEM/EMSC newsletter, 21, 3-6.

Wessel, P., and W.H.F. Smith (1998). New improved version of the generic mapping tools released, Eos Trans., AGU, $79,579$.

Westaway, R. (1990). Present-day kinematics of the plate boundary zone between Africa and Europe, from the Azores to Aegean, Earth Planet. Sci. Lett., 96, 393-406; doi:10.1016/0012-821X(90)90015-P.

Zoback, M.L. (1992). First- and second-order patterns of stress in the lithosphere: the world stress map project, J. Geophys. Res., 97, 11703-11728.

\footnotetext{
*Corresponding author: Luciano Scarfi, Istituto Nazionale di Geofisica e Vulcanologia, Osservatorio Etneo, Sezione di Catania, Catania, Italy; email: luciano.scarfi@ct.ingv.it.

(C) 2013 by the Istituto Nazionale di Geofisica e Vulcanologia. All rights reserved.
} 


\section{Appendix}

\section{The catalog}

The catalog presented here comprises focal solutions for about 300 earthquakes. Of these, slightly less than half refer to the Etna area. Figure 10 shows the frequency distribution of the events considered and successfully analyzed as a function of their magnitude (Figure 10a) and time (Figure 10b). A fairly steady increase in the number of solutions successfully obtained from 2004 can be noted, which can be attributed to the increase in the number of seismographs in operation, as well as to their technological upgrading. Geographic location is often a limiting factor. In particular, events that occurred in the Tyrrhenian Sea (except the area between the Aeolian Islands and the Gulf of Patti), and in the Channel of Sicily, and to a lesser extent in the Ionian Sea, suffer from an high azimuthal gap. In these instances, determination of the focal mechanism becomes more difficult. Conversely, the station coverage in central and western Sicily is improving, and currently it also allows the detection of events of low magnitude. Another element that sometimes limited the success ratio is that, particularly on Etna, earthquakes often occur as swarms (events very close in space and time), and their first arrivals at the stations can be blurred by the foreshock event.

Figure 11 shows some statistics about the quality of the mechanisms obtained. For most of the focal solutions, the range in the uncertainty of each parameter (strike, dip, rake) is within $15^{\circ}$, while the STDR is mostly higher than 0.6 to 0.7. A further test on the reliability of the focal mechanisms of the catalog was obtained by comparing our solutions with those of D'Amico et al. [2010] in the southern CalabriaPeloritan area, which were computed by the waveform inversion method. The comparison shows a good agreement for almost all of the mechanisms.

Finally, as for a given set of observed first motion polarities of an earthquake, multiple solutions that correspond to significant relative minima in misfit can be returned by FPFIT, we rejected calculations with more than two alternative solutions. When two solutions are identified for an event (about $20 \%$ for the current database), our choice of preference was carried out by considering the earthquake distribution, the comparison with data from the literature or other well-constrained mechanisms that lead to the same source area and the quality of each solution. The alternative focal mechanism is also reported in the catalog.

\section{Data distribution on the internet}

The catalog is available on the internet at http: / sismo web.ct.ingv.it/Focal/ and it is updated yearly. After having accessed the main page of the database, the data contained in the catalog can be viewed and extracted through the 'Catalog search' page. There, a main menu is displayed with some choices relating to the area of interest and the depth and
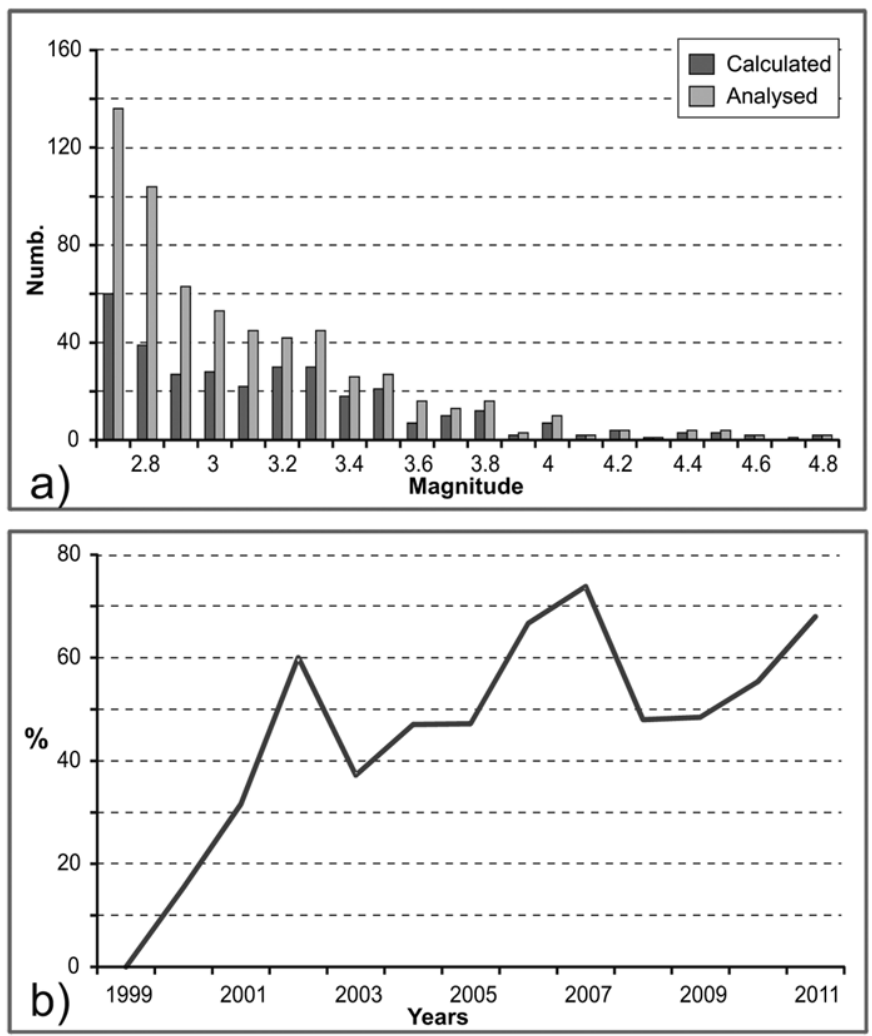

Figure 10. Comparison between the focal solutions computed and the analyzed events (as absolute values and percentage) as function of their magnitude (a) and time (b).
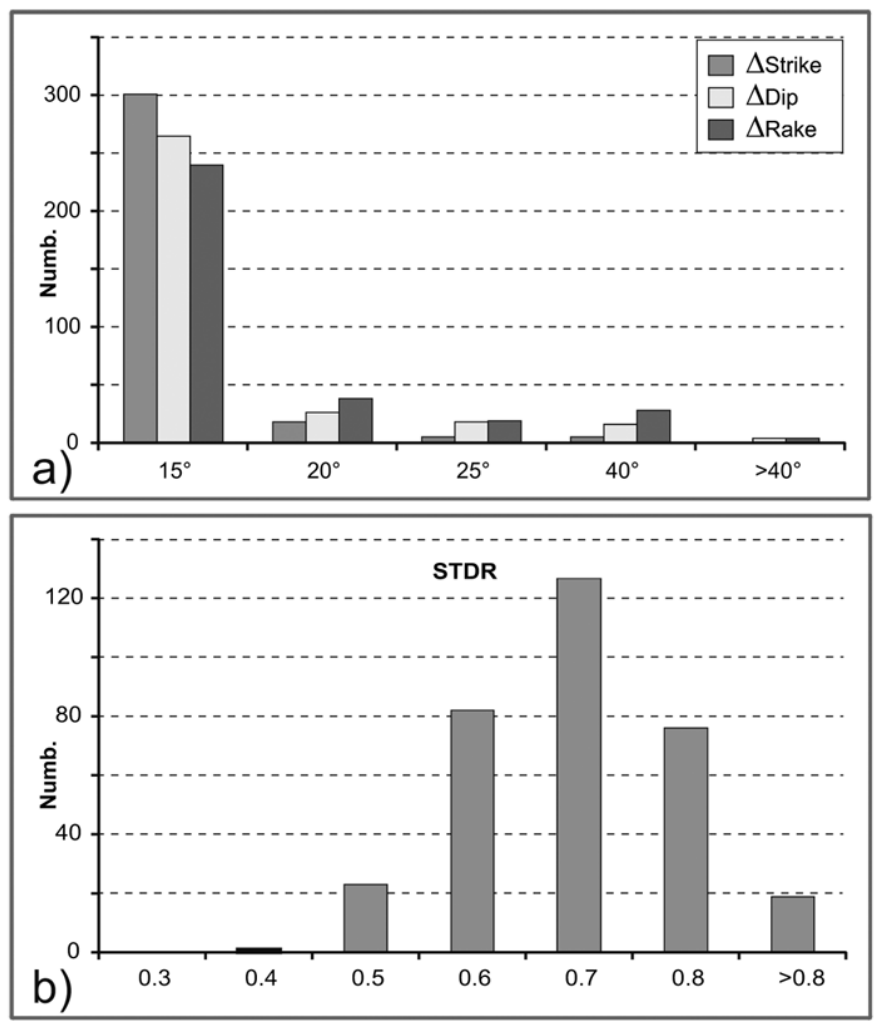

Figure 11. Distribution of (a) the uncertainty in the parameters (strike, dip, rake), and (b) the STDR of the focal solutions. 


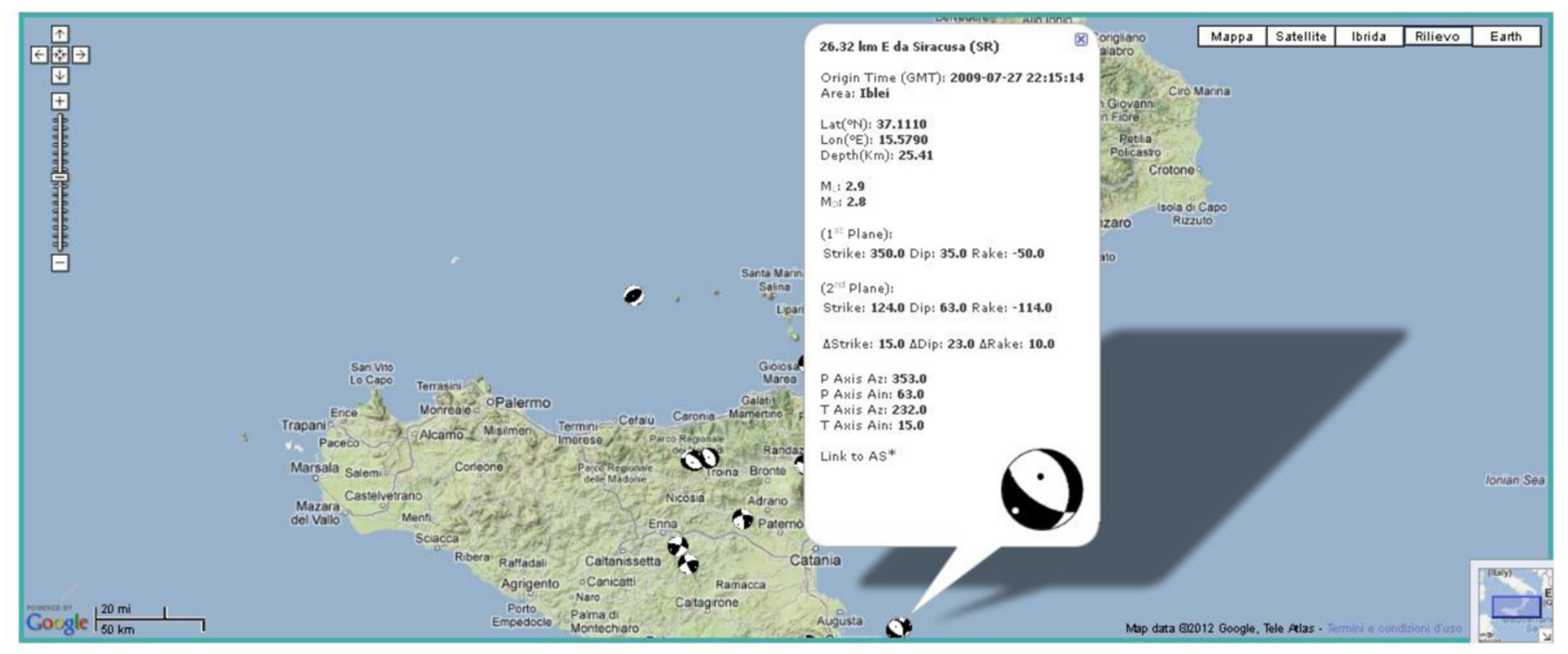

\begin{tabular}{|c|c|c|c|c|c|c|c|c|c|c|c|c|c|c|c|c|c|c|c|c|}
\hline DateTrine & Lat (N) & $\operatorname{Len}(\mathrm{E})$ & Dquth (Gin) & $M_{L}$ & $M_{p}$ & Strike & 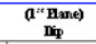 & Rabe & Strike & 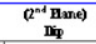 & Rake & astrike & $\Delta \mathrm{An}_{\mathrm{p}}$ & ARake & P Axis AX & F Axis Ain & TAvis Az & TAdis Ain & $\begin{array}{l}\text { Altenative } \\
\text { Schlitiens }\end{array}$ & Ing \\
\hline $2009 \cdot 07 \cdot 2300: 10: 42$ & 376 & 148 & 2335 & 3.7 & 35 & 3500 & 850 & -1500 & 2570 & 600 & .60 & so & 100 & 300 & 2180 & 250 & 1200 & 170 & AS* & $\theta$ \\
\hline 2009-07-27 22:15:14 & 37.1 & 156 & 25.41 & 29 & 28 & 350.0 & 350 & -500 & 1240 & 630 & -1140 & 150 & 230 & 100 & 3530 & 630 & 2320 & 150 & AS* & \\
\hline 2009-08-01 07:28:35 & 375 & 144 & 2322 & 2.7 & 26 & 200 & 300 & 100 & 2870 & 800 & 1600 & 50 & 250 & 30.0 & 3350 & 70 & 2420 & 210 & AS* & $\theta$ \\
\hline 2009-08-04 16:17:17 & 37.1 & 156 & 26.17 & 36 & 35 & 250 & 900 & -200 & 1150 & 700 & -1800 & 130 & 250 & 100 & 3380 & 140 & 720 & 140 & AS* & 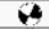 \\
\hline 2009-08-05 12:26:04 & 37.1 & 156 & 2595 & 28 & 29 & 20.0 & 70.0 & 0.0 & 2900 & 890 & 160.0 & 5.0 & 250 & 0.0 & 3370 & 130 & 243.0 & 150 & & $\theta$ \\
\hline $2009 \cdot 08 \cdot 25$ 16:58:02 & 378 & 15.1 & .038 & 36 & 33 & 2900 & 900 & 200 & 2000 & 700 & 1800 & so & 10.0 & 00 & 630 & 140 & 1570 & 140 & & \\
\hline $2009 \cdot 08 \cdot-2521: 07: 43$ & 378 & 15.1 & .0 .62 & 33 & 30 & 950 & 750 & .500 & 2020 & 420 & -1570 & 30 & 130 & so & 450 & 450 & 1560 & 200 & & c \\
\hline 2009-08-29 06:55:16 & 379 & 155 & 938 & 2.7 & 25 & 3350 & 250 & -1300 & 1980 & 710 & .730 & 130 & 30 & 200 & 132.0 & 610 & 2750 & 240 & & $O$ \\
\hline $2009 \cdot 10-0907: 05: 45$ & 374 & 145 & 1522 & 3.4 & 29 & 1550 & 800 & 1600 & 2490 & 700 & 110 & 30 & 100 & 50 & 2030 & 70 & 1110 & 210 & AS* & 6 \\
\hline $2009-10-1723: 53: 54$ & 370 & 15.1 & 18.16 & 3.1 & 29 & 1550 & 650 & 0.0 & 650 & 890 & 1550 & 100 & 10.0 & 200 & 1130 & 170 & 170 & 180 & & 8 \\
\hline $2009 \cdot 10 \cdot 1803: 44: 50$ & 370 & 15.1 & 17.17 & 3.4 & 3.1 & 800 & 900 & 1500 & 1700 & 600 & 0.0 & 50 & 80 & 1800 & 1290 & 210 & 310 & 210 & & \\
\hline $2009 \cdot 10-2517: 50: 27$ & 382 & 15.1 & 1459 & 30 & 2.7 & 800 & 70.0 & 40.0 & 3340 & 520 & 1550 & 30 & 30 & 0.0 & 203.0 & 110 & 3040 & 420 & As* & $\Leftrightarrow$ \\
\hline $2009 \cdot 10 \cdot 2817: 20: 02$ & 378 & 146 & 1105 & 30 & 29 & 140.0 & 50.0 & -100.0 & 3350 & 410 & -780 & 0.0 & 0.0 & 10.0 & 3580 & 810 & 2370 & 5.0 & AS* & $\boldsymbol{O}$ \\
\hline $2009 \cdot 10 \cdot 2907: 25: 45$ & 385 & 142 & 17.15 & 32 & 32 & 50.0 & 450 & 800 & 2440 & 450 & 100.0 & 180 & 150 & 200 & 1470 & 0.0 & 2410 & 830 & & - \\
\hline 2009-11-08 06:50:09 & 378 & 145 & 863 & 3.1 & 28 & 100 & 900 & 0.0 & 2800 & 890 & 180.0 & 50 & 150 & 200 & 1450 & 10 & 2350 & 10 & AS* & 6 \\
\hline 2009-11-08 06:51:15 & 378 & 145 & 779 & 4.4 & 40 & 1100 & 250 & -110.0 & 3120 & 660 & -810 & so & 80 & so & 2390 & 68.0 & 350 & 210 & & 9 \\
\hline
\end{tabular}

Figure 12. Search page of the web catalog presented in this study.

magnitude range of the events that the user wishes to consider. By clicking the 'Search' button, the data are returned in tabular and graphical format (Figure 12). The Table lists the main hypocentral and focal parameters of the selection; the map shows the beach balls of the same selection. Moreover, by clicking over a beach ball on the map, a pop-up menu is displayed, which contains the same information as in the Table, relating to that earthquake. In this way, the mechanisms are immediately usable for drawing maps or for making further computations. 